\title{
Элементы классической метрики в футуристическом воплощении ритма (на материале избранных произведений В. Хлебникова и М. Семенко)
}

\author{
Abstract \\ Elements of Classical Metrics in the Futuristic Rhythm Construction (Based on the Chosen \\ Works by Velemir Khlebnikov and Mikhajl Semenko)
}

The above work is an attempt to identify metric units characteristics of the classical poetry, especially the Greek one, in futuristic lyrics. The works by two outstanding representatives of Ukrainian and Russian futurism were analyzed. As for their construction, the verses have to be defined as polimetric. On the example of these verses it is possible to trace the sophisticated combination of metric units from which the classical Greek lyrics originated. Deliberate usage of the elements of Greek prosody is suppositional. Although this fact has been supported by certain evidence, it was never declared openly by the authors.

The problem of the presence of classical metric units in futuristic poetry has only been outlined in the present research. Undoubtedly it constitutes a vast area to be researched and opens the unexplored horizons of semantics hidden in the form of futuristic poetry.

Keywords: classical metrics, poetry, futuristic lyrics, Ukrainian and Russian futurism.

Значение ритма в авангардной лирике двадцатых годов XX века сформировалось на основе необычно глубокого понимания внутренних отношений между элементами произведения. Эта своеобразная философия в частности отражена в теоретических работах художника-супрематиста, Казимира Малевича. В статье $O$ новых системах в искусстве. Статика и скорость. Установление $A$. автор указывает на исходный пункт воспроизведения красоты в ключе авангарда, которым, по его словам, является принцип экономии. Энергия, которая прежде, в старом искусстве, была потрачена на излишнюю эстетику, теперь уходит внутрь произведения, сэкономлена внешней 
простотой формы ${ }^{1}$. Подобная констатация доказывает формальную, а также смысловую глубину в частности и футуристических стихов и указывает на то, насколько насыщенным и существенным является внутреннее движение элементов этого стиха, то есть его ритм.

В поэзии авангарда понятие ритма, в силу своей популярности, начинает приобретать мистические, магические, а даже религиозные черты. Малевич понятия ритма и темпа ставит наравне с символами религиозного культа. $\mathrm{B}$ статьях первых десятилетий XX века автор определяет ритм как фундамент церкви, которая в своей сущности ни что иное как движение ${ }^{2}$. Кроме того ощущение ритма у Малевича соединяет духовное и физическое начала человека, подлежащего влиянию факторов творческой силы, которая, по принципу замкнутого круга, подчиняется ритму и темпу. Эта сила, а главное, ее причины, являются новой верой нового человека ${ }^{3}$.

Магическое значение ритму придавал сам Велимир Хлебников, занимавшийся вычислениями законов времени и поисками формулы повторения исторических событий ${ }^{4}$. Поиски эти часто получали свое отражение в поэтических опытах на материале ритма, таких как палиндромические или полиметрические конструкции. Кроме того ритмику народных песенных мотивов, как некое семантизирующее средство, поэт неоднократно связывал с магическими заклинаниями, которые сопровождались у Хлебникова зачастую словотворческими опытами. Одним из наиболее ярких примеров использования ритмической ткани в подобном ключе является стихотворение 1913 года Ночь в Галиции 5 .

Понятие и функция ритма в авангардном лирическом тексте активно изучалось литературоведами, поэтами, представителями формальной школы и структурализма. Многие работы авторства Романа Якобсона, Юрия Тынянова, Евгения Поливанова, Осипа Брика, Льва Якубинского, Юрия Лотмана, Григория Винокура и многих других посвящены изучению и интерпретации звукового уровня стиха, его ритмической и метрической композиции.

Несмотря на то, что модернистское понятие ритма несомненно отличается отчетливой формальной свежестью и свободой, которая зачастую ведет к практически полному отрицанию традиционного толкования этого термина, нельзя не заметить некоторых сходств в авангардном и классическом восприятии ритма. Прежде всего следует подчеркнуть прямое отношение ритмических форм, используемых русскими модернистами, к их доисторическим аналогам. На подобное сходство указывают, например, результаты исследований Мечислава Порембского, который в своей статье, посвящен-

1 См.: K. Malewicz, O nowych systemach w sztuce. Statyka a szybkość. Ustanowienie A, пер. A.L. Piotrowska, A. Pomorski [в:] Kazimierz Malewicz, wiersze i teksty, ред. A. Pomorski, Warszawa 2004, c. 108.

2 См.: K. Malewicz, Poezja, пер. A.L. Piotrowska, A. Pomorski [в:] Kazimierz Malewicz, wiersze i teksty, ред. А. Pomorski, Warszawa 2004, с. 101.

3 См.: ibid., c. 95.

4 В виду имеются таки статьи В. Хлебникова, как Учитель и ученик. О словах, городах и народах 1912 года, Математическое понимание истории. Гамма будетлянина, 1919 года.

5 См.: В. Хлебников, Творения, ред. М. Поляков, Москва 1986, с. 90. 
ной метафоре, посредственно приходит также к характеристике ритмической ткани модернистского стиха. Ткань эта напоминает не сверхустановленный порядок чередующихся секвенций, а является воспроизведением древних хаотических импульсов, являющихся интуитивным отображением окружающего мира 6 . На оппозицию ритма хаотического, как характерного древнему мироощущению, и упорядоченного, являющегося триумфом культуры над стихией природы, указывает Владимир Топоров в своих исследованиях, посвященных поискам источников поэтических символов в эпохе палеолита ${ }^{7}$.

Следует предполагать, что подобное толкование ритма было близко футуристам. Об этом свидетельствует почитаемый ими принцип недискурсивности структуры произведения, т.е. освобождения поэзии от образцов логического мышления ${ }^{8}$. Этот прием давал удивительные результаты, как, например, ассоциативность подбора составляющих композиции или придавание значения самым маленьким элементам языковой структуры - фонемам. Но одним из наиболее значимых проявлений подобных действий является отказ от норм синтаксиса, что вызывает впечатление возвращения к элементарным языковым формам 9

Известно однако, что для футуристической лирики характерна высокая степень внутренней противоречивости. Именно поэтому, несмотря на почти полное отрицание традиционных образцов как русскими, так и украинскими футуристами, в творчестве почти всех представителей этого движения слышны отголоски классических правил строения стиха. У Хлебникова на подобные сходства указывает, например, Борис Эйхенбаум в статье $O$ прозе и поэзии, сравнивая творчество поэта с канонами поэзии XVIII века ${ }^{10}$. О Михайле Семенко как о „футуристе и антикваре” одновременно говорит Мыкола Сулыма в статье Три этапа украинского футуризма, подчеркивая наличие в поэтическом наследии поэта и сонетов, и верлибров, и произведений, написанных ямбом, хореем или амфибрахием ${ }^{11}$. Несомненно особую ценность в творчестве обоих поэтов представляет ритмический строй лирических произведений, который неоднократно был исследован многими стиховедами. Ритмика Хлебникова в частности была предметом научных трудов таких исследователей, как упомянутые уже Роман Якобсон, указывающий на роль подсознания в композиции стиха ${ }^{12}$ и Григорий Винокур, занимающийся преимущественно вопросами соотношения между формой и содержанием

6 См.: M. Porębski, Czy metaforę można zobaczyć, „Teksty” 1980, nr 6 (54), c. 64-65.

7 См.: В. Топоров, К происхождению некоторых поэтических символов. Палеолитическая эпоха [в:] Ранние формы искусства, ред. Е. Мелетинский, Москва 1972, с. 78.

${ }^{8}$ Cм.: Z. Jarosiński, Postacie poezji, Warszawa 1985, s. 47.

9 См.: ibid., c. 49-50.

10 См.: Б. Эйхенбаум, Творчество Юрия Тынянова [в:] О прозе. О поэзии, ред. О. Эйхенбаум, Ленинград 1986, с. 195.

${ }_{11}$ См.: М. Сулима, Три етапи украӥнського футуризму [в:] Украӥнський футуризм. Вибрані сторінки, под ред. М. Сулима, Ніредьгаза 1996, с. 10.

12 См.: Р. Якобсон, Из мелких вещей Велимира Хлебникова: «Ветер-пение...» [в:] Работы по поэтике, под ред. М. Гаспаров, Москва 1987, с. 317-323. 
произведений поэта ${ }^{13}$. Тема микрополиметрических систем в лирике Хлебникова была развита Михаилом Гаспаровым в книге Русские стихи 1890-х - 1925-го годов в комментариях ${ }^{14}$. Михаил Панов, в свою очередь, в статье Сочетание несочетаемого обращает внимание на проблему соединения отдельных метров в поэзии Хлебникова по принципу фузионности ${ }^{15}$.

Поэтика Михайля Семенко является отражением эволюции, которой подлежал украинский футуризм, начиная с раннего периода кверофутуризма, т.е. поисков новых формальных методов и отрицания классики, через этап восхищения культурой Дальнего Востока в 1914 году, и заканчивая грандиозной идеей панфутуризма двадцатых годов и конструктивизмом 1924 года ${ }^{16}$. Разные аспекты лирики Семенко были исследованы в частности в работах Анны Билой, Олега Ильныцкого, а также дочери поэта, Ирины Семенко, пишущей под псевдонимом Leo Kriger.

Настоящая статья, в свою очередь, является попыткой выявления некоторых сходств в ритмическом строении стихов двух этих выдающихся поэтов, погруженных в разные культурные пространства и контексты, с греческим прообразом, столь близким славянской языковой культуре. Факт существования подобных сходств является в данном случае только предположением, так как не существует однозначных сведений, подтверждающих осознанное употребление футуристами элементов греческой метрики. Наоборот, чаще всего в их лирике можно заметить тонические, ориентированные на акцентное сходство, а не силлаботонические системы. Кроме того, многие из них, как, на пример, Владимир Маяковский в статье Как делать стихи, громко заявляли о довольно пренебрежительном отношении к точным размерам. Предположение же о возможности существования в футуристической лирики неких аналогичных к греческой метрике явлений вытекает из вышеупомянутого парадоксального стремления представителей авангарда отыскать утраченные во время десятилетий использования языка его особые свойства. Поиски эти зачастую были устремлены в древность, а это в какой-то мере позволяет предполагать некое родство з классическим образом метра.

$\mathrm{B}$ связи со спецификой лирики XX века, в данной работе во внимание будут приниматься полиметрические конструкции метра, которые, особенно у Хлебникова, приобретают весьма своеобразную форму.

Хлебниковская полиметрия сильно отличается от классической своей дефиниции. Она уже не напоминает композицию с определенными метрическими сегментами, которые чередуются в соответствии со смысловой структурой. Здесь отдельные метрические стопы заменяют друг друга непосредственно, хаотично, на уровне самых коротких отрезков текста. При этом полная свобода соединения метрических единиц сопровождается пре-

13 См.: Г. Винокур, Хлебников «Вне времени и пространства» [в:] Филологические исследования. Лингвистика и поэтика, ред. Г. Степанов, В. Нерознак, Москва 1990, с. 250-253.

14 См.: М. Гаспаров, Русские стихи 1890-х-1925-го годов в комментариях, Москва 1993.

15 См.: М. Панов, Сочетание несочетаемого [в:] Мир Велимира Хлебникова. Статьи, исследования 1911-1998, ред. Вяч. Иванов, 3. Паперный, А. Парнис, Москва 2000, 303-332.

16 См.: М. Семенко, Вибрані твори, ред. А. Білої, Київ 2010, с. 5-15. 
обладанием одного типа стихосложения, который становится своеобразным метрическим фоном ритмического строя стиха ${ }^{17}$.

Хорошим примером хлебниковской полиметрии может послужить стихотворение Кузнечик:

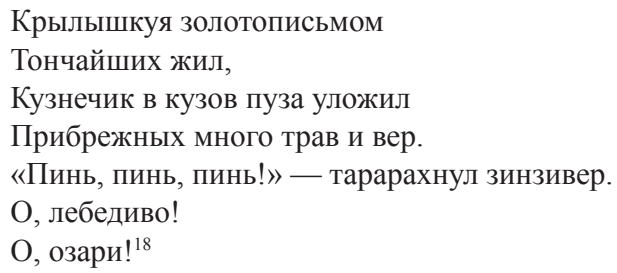

В первых четырех строках этого стихотворения чередование метрических единиц происходит довольно равномерно, хотя первая строка, составленная из двух пеонов первых, поражает непривычным для уха количеством безударных слогов. Следующие строки являются последовательным, соответственно двух- пяти- и четырехстопным ямбом с акаталектикой, который и можно считать своеобразным метрическим фоном. Следует заметить, что в классической греческой метрике ямб является одним из наиболее широко используемых размеров. Его примеры в поэзии Архилоха из VII века до нашей эры свидетельствуют о том, какой длинный путь совершенствования был пройден этим размером, от свободного народного ямба, до литературного ямбического образца, подлежащего множеству метрических правил ${ }^{19}$.

В приведенном примере, в четвертой строке можно заметить наличие ямбического акаталектического диметра. В древнегреческой лирике такой размер часто появлялся в качестве эпода после ямбического триметра. Его зачастую использовали в лирических партиях драмы или в комедии, после партий, написанных ямбическим тетраметром. В таких случаях ямбический акаталектический диметр образовывал очень длинные системы диалогов ${ }^{20}$. Однако в приведенном примере появляется только один такого рода классический размер, поэтому его функцию можно сравнить здесь с функцией эпода, который является своего рода заключением некого большего целого.

И действительно, после ямбического диметра с акаталектикой, следующая строка внезапно начинается с моллоса. Согласно греческому образцу моллос является результатом синкопы нейтрального слога так называемого лирического хорея ${ }^{21}$. Само явление синкопы в таком случае является характерной чертой трагедии, а что касается более общего толкования этого термина, он связан с техниками избегания хиатуса ${ }^{22}$. Если посмотреть на синко-

17 См.: W. Chołszewnikow, Zarys wersyfikacji rosyjskiej, пер. J. Faryno [в:] Poetyka: Zarys encyklopedyczny, ред. L. Pszczołowska, Wrocław 1976, с. 79.

18 В. Хлебников, ор. cit., с. 55.

19 См.: Н. Sądejowa, Zarys metryki greckiej [в:] Metryka grecka i tacińska, ред. M. Dłuska, W. Strzelecki, Wrocław 1959, c. 22.

20 См.: ibid., c. 28.

21 См.: ibid., c. 34.

22 См.: ibid., c. 9. 
пу с модернистской точки зрения, то можно толковать ее как своеобразный сдвиг на уровне метрики, что придает моллосу в начале пятой строки особое, в некоторой степени пластическое движение.

Размер следующей части строки определить очень сложно, так как ее сопоставление с предыдущим трехударным слогом совершенно разрушает любое ритмическое ожидание. Вероятнее всего две последние стопы этой строки можно считать резким столкновением пеона третьего с анапестом. Подобное суждение обосновано в большей мере интонационной инерцией.

Однако наиболее интересными по своему метрическому строю оказываются две последние строки, образующие хориямбы. Классический хориямб является диметром и состоит из восьми слогов. В Кузнечике классический хориямбический диметр расчленяется на две части благодаря делению строк. Первая его часть продолжена в клаузуле одним безударным слогом, что меняет классическую форму хориямба. Подобный факт, однако, не вызывает удивления, так как хориямбический диметр очень редко состоит из двух чистых хориямбов. Часто первая часть хориямбической диметрической строки может подлежать метрическому изменению. Поэтому, если принять, что две последние строки были бы нераздельны, своей формой они очень напоминали бы эольский размер 23 .

Нет сомнений, что в метрике этого чисто футуристического стихотворения, исполненного неологизмов и звукоподражаний, есть много сходного с классической греческой метрикой.

Ярким, хотя одним из немногих примеров полиметрии в раннем периоде творчества Семенко, являеется стих Голос мая:

I я, і Ви - почули голос мая,

Щось затремтіло — там, біля серця.

Мчимо в хвилях мототрамвая.

Почнемо інтермеццо.

Ми в Дарниці. Так гарно. Мило.

Пахучососни. Гуляємо. Десь плеще.

Груди затопило...

Ви: «Що се ще?»

Ми поверталися. Ні слова. Кепсько.

Безмовно йшли. Прощались біля ліфта.

I зникли Ви. I зник кудись Семенко.

...Дома я взявсь за Свіфта ${ }^{24}$.

Уже в 1914 году одной из любимых стихотворных форм поэта являлся верлибр, отличающийся структурой кинематографических кадров, создающих специфический ритм благодаря многочисленным анафорам и внутрен-

23 См.: ibid., c. 40.

24 М. Семенко, ор. cit., с. 30. 
ним созвучиям ${ }^{25}$. Несмотря на это, в творчестве Семенко можно найти примеры и полиметрии и классической силлаботоники.

Пример Голоса мая показывает некое сходство между полиметрическими приемами Семенко и Хлебникова. Об этом свидетельствует, например, накопление разных метрических структур на небольшом фрагменте текста, или размытая, а часто и вовсе отсутствующая семантическая мотивация перемены метра. Однако есть и существенные различия: Хлебников использует и свободно соединяет на много больше размеров, которые с точки зрения классической метрики очень редко бывают сопоставляемы, как, например, размещение в рамках одной строки моллоса, являющегося разновидностью хореического метра (хореический метр в своем классическом образце состоит из двух стоп $-\mathrm{U}-\mathrm{U}^{26}$ ) и четырехсложного размера (например пятая строка стихотворения Кузнечик). У Семенко перемены метра не столь резкие и более упорядоченные. Однако у обоих поэтов можно попытаться найти некие сходства с классической метрикой древнегреческой лирики.

Первая строка Голоса мая состоит из классического пятистопного ямба с гиперкаталектикой в клаузуле. Наличие точно такого же размера во второй и третьей строках последней строфы является доказательством следующего сходства с лирикой Хлебникова - расшатанная метрическая структура получает своеобразный постоянный метрический фон, в этом случае - ямбический. На нем чередуются различные метры, придающие ритмическую свежесть и необычность тексту.

Вторая строка первой строфы является примером дактилического каталектического диметра с усечением одного безударного слога в каждой из частей диподии ${ }^{27}$. Характерно, что строка разделена цезурой и если рассматривать ее с точки зрения античной метрики, то следует заметить, что конец слова перед цезурой сходится с концом стопы, что позволяет предполагать диерезу ${ }^{28}$.

За столь упорядоченным строем следуют две последние строки первой строфы, которые полностью разрушают ритмическое ожидание, созданное в начале.

В предпоследней строке бакхий сменяется двумя амфибрахиямии. Стоит заметить, что в греческой поэзии использование бакхия наблюдалось крайне редко. Конечно же нельзя сравнивать единичной бакхической стопы с античными бакхическими ди- или тетраметрами, однако некое сходство можно заметить в семантической предрасположенности. Бакхий был использован чаще всего в греческих трагедиях, при чем всегда в моменты большого эмоционального напряжения ${ }^{29}$. В стихотворении Семенки бакхический раз-

25 См.: L. Kriger, Михайль Семенко (1892-1937) - основоположник Українського футуризму [в:] Михайль Семенко: Вибрані твори, ред. А. Білої, Київ 2010, с. 578.

26 См.: H. Sądejowa, op. cit., c. 31.

27 См.: ibid., c. 19.

28 См.: ibid., c. 77.

29 См.: ibid., c. 56. 
мер подчеркивает динамику движения, является своеобразной кульминацией строфы.

Если же на бакхий посмотреть сквозь призму латинской метрики, то легко заметить, что этот размер ни что иное, как ямбический монометр, в котором второй безударный слог редуцирован ${ }^{30}$. Эта перспектива указывает на особое сходство третьей строки с метрическим фоном, построенном на ритме ямба.

Особый интерес представляет последняя строфа, состоящая из четырех строк, три первые из которых насчитывают по одиннадцать слогов, что в некоторой степени напоминает традиции силлабизма XVII-XVIII веков, при чем не следует забывать о народном происхождении одиннадцатисложника $^{31}$. Однако, во-первых, у Семенки нет обязательной в силлабизме цезуры, a, во-вторых, силлаботонический строй здесь очень выразителен. Двойной, уже упомянутый, пятисложный ямб окаймлен с двух сторон комбинацией дактилей и хореев.

Несмотря на ритмическую расшатанность последней строфы, ее целостность удается удержать благодаря женской клаузуле во всех последующих строках, а также внутреннему синтаксическому членению двух ямбических строк, создающему впечатление своеобразной мужской цезуры ${ }^{32}$. Эта внутренняя неоднородность окончания стихотворных единиц придает всей строфе особую динамичность и отрывистость, которая все-таки остается одним целым.

В творчестве обоих поэтов, произведения которых подлежали анализу в данной работе, несомненно можно найти некие общие черты для классической, греческой и латинской, а также авангардной метрики. Возможно такие сходства возникли подсознательно и не были намеренным действием автора. Однако их следы в творчестве футуристов являются доказательством того, что независимо от громких манифестов и всеобщего отрицания и разрушения, культурное мировое наследие все-таки не было сброшено с „Парохода современности”.

Описанные здесь примеры поисков отголосков классической метрики в крике футуристического стиха являются лишь небольшим лучом, брошенным на обширную проблему парадоксального черпания авангардных образцов новых форм из классического понимания искусства. Эта тема несомненно требует дальнейшего развития.

30 См.: W. Strzelecki, Zarys metryki łacińskiej [w:] Metryka grecka i łacińska, ред. M. Dłuska, W. Strzelecki, Wrocław 1959, c. 77.

31 См.: А. Квятковский, Поэтический словарь, ред. И. Роднянской, Москва 1966, с. 179.

32 См.: H. Sądejowa, op. cit., Wrocław 1959, с. 77. 


\section{Библиография}

Винокур Г., Хлебников «Вне времени и пространства» [в:] Филологические исследования. Лингвистика и поэтика, ред. Г. Степанов, В. Нерознак, Москва 1990.

Семенко М., Вибрані твори, ред. А. Білої, Київ 2010.

Chołszewnikow W., Zarys wersyfikacji rosyjskiej, пер. J. Faryno [в:] Poetyka: Zarys encyklopedyczny, ред. L. Pszczołowska, Wrocław 1976.

Сулима М., Три етапи українського футуризму [в:] Український футуризм. Вибрані сторінки, под ред. М. Сулима, Ніредьгаза 1996.

Гаспаров М., Русские стихи 1890-х-1925-го годов в комментариях, Москва 1993.

Эйхенбаум Б., Творчество Юрия Тынянова [в:] О прозе. О поэзии, ред. О. Эйхенбаум, Ленинград 1986.

Якобсон Р., Из мелких вещеей Велимира Хлебникова: «Ветер-пение...» [в:] Работы по поэтике, ред. М. Гаспаров, Москва 1987.

Хлебников В., Творения, ред. М. Поляков, Москва 1986.

Jarosiński Z., Postacie poezji, Warszawa 1985.

А. Квятковский, Поэтический словарь, ред. И. Роднянской, Москва 1966.

Kriger L., Михайль Семенко (1892-1937) - основоположник Українського футуризму [в:] Михайль Семенко: Вибрані твори, ред. А. Білої, Київ 2010.

Malewicz K., O nowych systemach w sztuce. Statyka a szybkość. Ustanowienie A, пер. A.L. Piotrowska, A. Pomorski [в:] Kazimierz Malewicz, wiersze i teksty, ред. A. Pomorski, Warszawa 2004.

Malewicz K., Poezja, пер. A.L. Piotrowska, A. Pomorski [в:] Kazimierz Malewicz, wiersze i teksty, ред. А. Pomorski, Warszawa 2004.

Панов М., Сочетание несочетаемого [в:] Мир Велимира Хлебникова. Статьи, исследования 1911-1998, ред. Вяч. Иванов, З. Паперный, А. Парнис, Москва 2000.

Porębski M., Czy metaforę można zobaczyć, „Teksty” 1980, nr 6 (54).

Sądejowa H., Zarys metryki greckiej [в:] Metryka grecka i łacińska, ред. M. Dłuska, W. Strzelecki, Wrocław 1959.

Strzelecki W., Zarys metryki łacińskiej [w:] Metryka grecka i łacińska, ред. M. Dłuska, W. Strzelecki, Wrocław 1959.

Топоров В., К происхождению некоторых поэтических символов. Палеолитическая эпоха [в:] Ранние формы искусства, ред. Е. Мелетинскый, Москва 1972. 